\title{
The effect of warmth acclimation on behaviour, thermophysiology and perception
}

Citation for published version (APA):

Pallubinsky, H., Kingma, B. R. M., Schellen, L., Dautzenberg, B., van Baak, M. A., \& van Marken Lichtenbelt, W. D. (2017). The effect of warmth acclimation on behaviour, thermophysiology and perception. Building Research and Information, 45(7), 800-807.

https://doi.org/10.1080/09613218.2017.1278652

Document status and date:

Published: 01/01/2017

DOI:

10.1080/09613218.2017.1278652

Document Version:

Publisher's PDF, also known as Version of record

Document license:

Taverne

Please check the document version of this publication:

- A submitted manuscript is the version of the article upon submission and before peer-review. There can be important differences between the submitted version and the official published version of record.

People interested in the research are advised to contact the author for the final version of the publication, or visit the DOI to the publisher's website.

- The final author version and the galley proof are versions of the publication after peer review.

- The final published version features the final layout of the paper including the volume, issue and page numbers.

Link to publication

\footnotetext{
General rights rights.

- You may freely distribute the URL identifying the publication in the public portal. please follow below link for the End User Agreement:

www.umlib.nl/taverne-license

Take down policy

If you believe that this document breaches copyright please contact us at:

repository@maastrichtuniversity.nl

providing details and we will investigate your claim.
}

Copyright and moral rights for the publications made accessible in the public portal are retained by the authors and/or other copyright owners and it is a condition of accessing publications that users recognise and abide by the legal requirements associated with these

- Users may download and print one copy of any publication from the public portal for the purpose of private study or research.

- You may not further distribute the material or use it for any profit-making activity or commercial gain

If the publication is distributed under the terms of Article $25 \mathrm{fa}$ of the Dutch Copyright Act, indicated by the "Taverne" license above, 


\title{
The effect of warmth acclimation on behaviour, thermophysiology and perception
}

\author{
Hannah Pallubinsky (i) ${ }^{a}$, Boris R. M. Kingma ${ }^{a}$, Lisje Schellen ${ }^{a, b}$, Bas Dautzenberg ${ }^{a}$, Marleen A. van Baak ${ }^{a}$ and \\ Wouter D. van Marken Lichtenbelt ${ }^{\mathrm{a}}$ \\ ${ }^{a}$ Department of Human Biology and Movement Sciences, NUTRIM, Maastricht University, Maastricht, the Netherlands; ${ }^{b}$ School of Built \\ Environment and Infrastructure, Avans University of Applied Sciences, Tilburg, the Netherlands
}

\begin{abstract}
Public and commercial buildings tend to overheat and considerable energy is consumed by airconditioning and ventilation. However, many occupants remain unsatisfied and consequently exhibit thermoregulatory behaviour (TRB), e.g. opening windows or controlling the airconditioning. This, in turn, might negatively influence the building energy use. This paper hypothesizes that warmth acclimation influences thermophysiology, perception and TRB in a warm environment. Therefore, the effect of warmth acclimation on TRB, physiology and perception is investigated. Twelve participants underwent a so-called SWITCH protocol before and after warmth acclimation ( 7 days, $6 \mathrm{~h}$ /day, about $33^{\circ} \mathrm{C}$, about $22 \% \mathrm{RH}$ ). During SWITCH, the participants chose between a warm $\left(37^{\circ} \mathrm{C}\right)$ and a cold $\left(17^{\circ} \mathrm{C}\right)$ condition. TRB was determined by the number of switches and the time spent in a specific condition. Mean skin temperature was recorded to assess behavioural thresholds. Thermal comfort and sensation were indicated on visual analogue scales (VAS). After acclimation, the upper critical behavioural threshold significantly increased from $35.2 \pm 0.6$ to $35.5 \pm 0.5^{\circ} \mathrm{C}(p \leq 0.05)$ and the range of mean skin temperatures at which no behaviour occurred significantly widened (3.6 \pm 0.7 to $4.2 \pm 0.6 ; p<$ $0.05)$. The total number of switches tended to decrease $(p=0.075)$. The present study is the first to show that prolonged passive exposure to warmth extends TRB thresholds.
\end{abstract}

\section{KEYWORDS}

adaptation; adaptive behaviour; energy demand; overheating; physiology; thermal comfort; thermoregulatory behaviour; warmth acclimation

\section{Introduction}

In temperate climate zones, public and commercial buildings tend to overheat due to, amongst other things, highly insulating construction materials, high internal heat loads and the progression of global warming (Lomas \& Porritt, 2017; IPCC, 2013). Approximately one-third of the primary energy supply in the Western world is used for air-conditioning and ventilation of buildings, mostly to ensure occupant comfort (IEA, 2011). However, a great number of building occupants remain unsatisfied with the thermal environment. People nowadays spend most of the day indoors (Klepeis et al., 2001) and therefore it is of particular interest to study the interactions of people and their thermal environment to create a well-balanced and energy-effective indoor ambience. The present paper focuses on the impact of prolonged exposure to relatively warm temperatures on autonomous (physiological) and conscious (behavioural) human thermoregulation and temperature perception.

\section{Thermoregulatory behaviour in the built environment}

Building occupants are mainly exposed to fixed indoor temperatures $\left( \pm 0.5^{\circ} \mathrm{C}\right)$, as recommended by international standards (ASHRAE, 2010). These standards are mostly intended to create a thermoneutral environment, but the application of those standards is, nevertheless, often not a guarantee for acceptable and adequate indoor temperatures. Consequently, building occupants frequently influence their thermal environment by, for example, opening a window or controlling the air-conditioning in order to maximize thermal acceptability and to improve satisfaction. Those actions can be referred to as thermoregulatory behaviour (TRB). Importantly, the indoor climate of a building can affect the human metabolism and related biological processes and uncomfortable warm environments might cause sleepiness and restrict productivity (de Dear et al., 2013). Therefore, it is important to ensure optimal 
indoor conditions to guarantee a healthy and stimulating work environment.

TRB might, however, in turn, affect heating, ventilation and air-conditioning (HVAC) performance and thereby influence energy expenditure and energy costs of the building. Knowledge gaps regarding the mechanisms and driving forces of TRB make it a rather difficult factor to predict. The lack of possibilities to predict TRB also makes it difficult to foresee the impact of TRB on the energy use of a building. TRB might influence building energy use when occupants are able to interfere with the system, since TRB might cause a discrepancy between the predicted and the actual energy consumption of a building. More insight into mechanisms and triggers of TRB provides the opportunity to improve building energy simulation models by including user characteristics, since the current models are often lacking this information. The latter stresses the need for a better understanding of the interplay between the occupant and the respective building to prevent a wasteful use of resources and to reduce energy costs.

\section{Thermoregulatory behaviour, thermophysiology and thermal perception}

In order to comprehend the mechanisms of TRB, it is essential to understand the controlling factors. TRB is greatly determined on autonomously regulated physiological processes of the human body. Changes of core and skin temperature have previously been identified as the main driving forces of TRB (Cabanac, Cunningham, \& Stolwijk, 1971; Chatonnet, Thiers, Cabanac, \& Pasquier, 1966). More recently, Schlader et al. (2013) have indicated that especially in mild thermal environments, skin temperature is the primary initiator of TRB. However, the mechanisms that actually control TRB and the respective thresholds that must be reached or exceeded before behaviour is initiated remain ambiguous. Apart from the physiological determinates, another important factor for TRB is the subjective perception of a thermal environment, expressed by, for example, thermal sensation (TS) and thermal comfort (TC) (Gagge, Stolwijk, \& Hardy, 1967; Schlader, Simmons, Stannard, \& Mundel, 2011). When TS progresses away from neutral and/or an environment is perceived as being 'uncomfortable', TRB is likely to occur (Jacquot, Schellen, Kingma, van Baak, \& van Marken Lichtenbelt, 2014). The latter implies that TRB is not solely initiated and influenced by physiological reactions but is part of a complicated synergy of physiological, conscious and subconscious factors.

\section{Thermoregulatory behaviour and heat acclimation}

Due to the increasing risks for the overheating of buildings, it is important to study the impact of prolonged exposure to warmth on the human metabolism and the thermoregulatory system (AECOM, 2012; Lomas \& Porritt, 2017). Heat acclimation has been studied for many years, yet there is a distinct lack of information on the effect of prolonged warmth exposure on TRB and subjective perception. Traditionally, heat acclimation studies were designed to develop active acclimation models for miners, athletes or the military (Taylor, 2014). The majority of such studies used exercise-induced hyperthermia combined with high ambient temperatures to reach adaptations at various levels of the thermoregulatory system, but also includes non-exercise studies where hypothermia was induced by sitting in a warm bath (Edholm \& Weiner, 1981; Fox, Goldsmith, Kidd, \& Lewis, 1963; Turk \& Thomas, 1975). These adaptations include changes in core temperature, skin temperatures, evaporative heat loss, the cardiovascular system and other metabolic functions; and they result in a superior ability to dissipate heat. However, where exercise is used as an additional heat stimulus, it is difficult to distinguish between temperature- and exercise-related adaptations of the thermoregulatory system. Strikingly, information on the effects of prolonged mild passive exposure to warmth is very limited. To the best of the authors' knowledge, no information exists on the effect of such mild warmth acclimation (neither active nor passive) on human TRB. To gain important insights for the built environment sector, it is desirable to test the effects of mild, and thus more realistic, ambient conditions on the human thermoregulatory system on both the autonomous and conscious parts.

Following the above, the present authors hypothesize that warmth acclimation might influence TRB by modulating skin temperature and thermal perception. Therefore, they investigated the effect of mild passive warmth acclimation on TRB, skin temperature and thermal perception.

\section{Methods}

The experiments presented in this paper are part of an extensive study designed to evaluate the effects of passive warmth acclimation on thermal physiology, TC and TRB. In the scope of this paper, we focus on the behavioural part of the experiment.

All experiments were performed at the Metabolic Research Unit of Maastricht University (MRUM) between December 2014 and August 2015. During this 
Table 1. Participant characteristics.

\begin{tabular}{ll}
\hline Age (years) & $24.1 \pm 3.1$ \\
Height $(\mathrm{m})$ & $1.79 \pm 0.07$ \\
Weight $(\mathrm{kg})$ & $73.6 \pm 9.7$ \\
BMI $\left(\mathrm{kg} / \mathrm{m}^{2}\right)$ & $23.0 \pm 3.0$ \\
Fat $(\%)$ & $19.8 \pm 2.9$ \\
Fat mass $(\mathrm{kg})$ & $14.9 \pm 3.4$ \\
\hline
\end{tabular}

Note: Data are presented as the mean \pm SD. $N=12$.

period, 12 young healthy male volunteers visited the MRUM for nine consecutive days. Their characteristics are provided in Table 1. Fat percentage and fat mass were determined by dual-energy X-ray absorptiometry (DEXA).

All volunteers were healthy, normotensive, nonobese, non-smokers and not taking any medication that might have altered their cardiovascular system or thermoregulatory responses. The participants refrained from food, alcoholic and caffeinated beverages as of 22:00 hours the evening before being measured. For the behavioural experiment, they underwent two testing days ( 1 and 9) and seven days of warmth acclimation (Figure 1(a)). During days 1 and 9, the SWITCH protocol was performed.

\section{The SWITCH protocol}

The SWITCH protocol (Figure 1(a and b)) was performed to evaluate TRB before and after warmth acclimation. SWITCH was conducted in two climate chambers

(a)

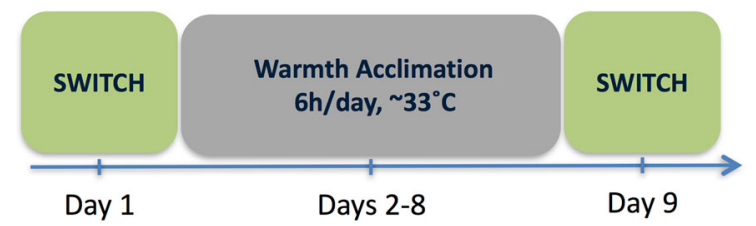

(b)

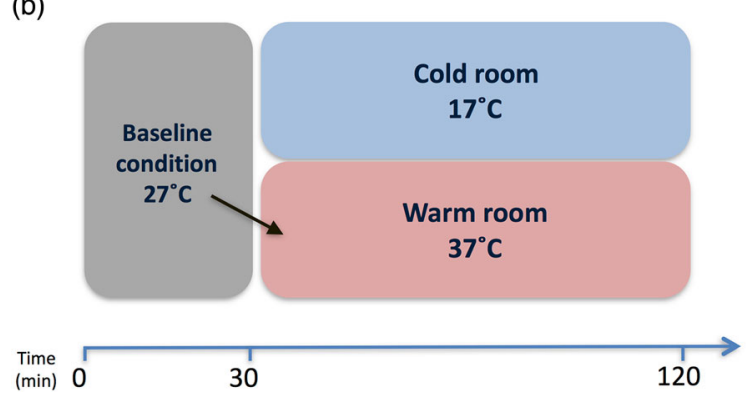

Figure 1. (a) Time-course of the study; and (b) the SWITCH protocol. After $30 \mathrm{~min}$ of baseline, participants were free to switch between a warm and a cold room; there were no limits with respect to frequency or time. The black arrow indicates the start condition. of the MRUM (Figure 2(a)). Before commencing SWITCH, participants acclimatized in the baseline condition $\left(27^{\circ} \mathrm{C}\right.$ ambient temperature) for $30 \mathrm{~min}$ in order to ensure a comparable starting situation. After $30 \mathrm{~min}$, they were guided to a warm room $\left(37^{\circ} \mathrm{C}\right)$. They were instructed that as of that very moment, they were free to switch between the warm room $\left(37^{\circ} \mathrm{C}\right)$ and a cold room $\left(17^{\circ} \mathrm{C}\right)$, without any limitation to the number of switches or the time between switches. Moreover, the participants were informed that they could switch between the warm and the cold conditions without notifying the researcher, whenever they wanted, simply by opening the door by themselves and walking into the other room. The latter was considered to be of great importance in order to ensure that participants actually perceived the freedom to express TRB without feeling monitored. SWITCH continued for $90 \mathrm{~min}$. During measurements, participants were instructed to remain seated at a desk whilst remaining in one of the rooms (Figure 2(b)) and they were allowed to perform reading tasks (1.2 metabolic equivalent of tasks (METs)). Watching television or browsing the internet was prohibited in order to minimize the risk of distraction.

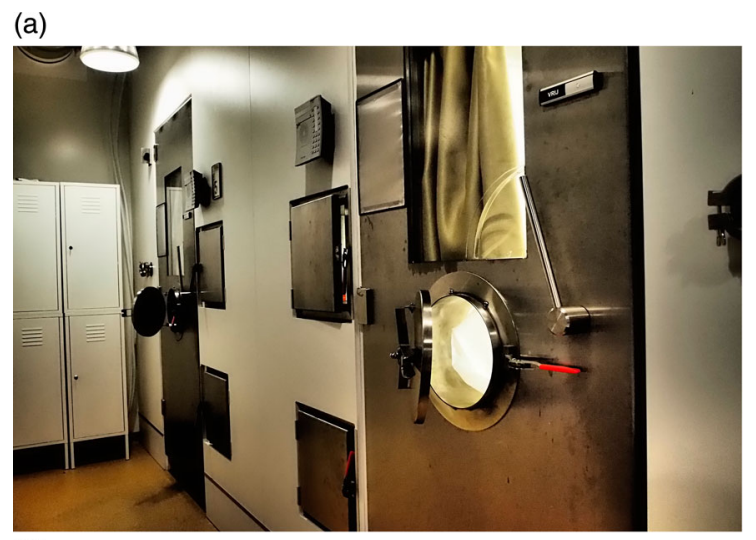

(b)

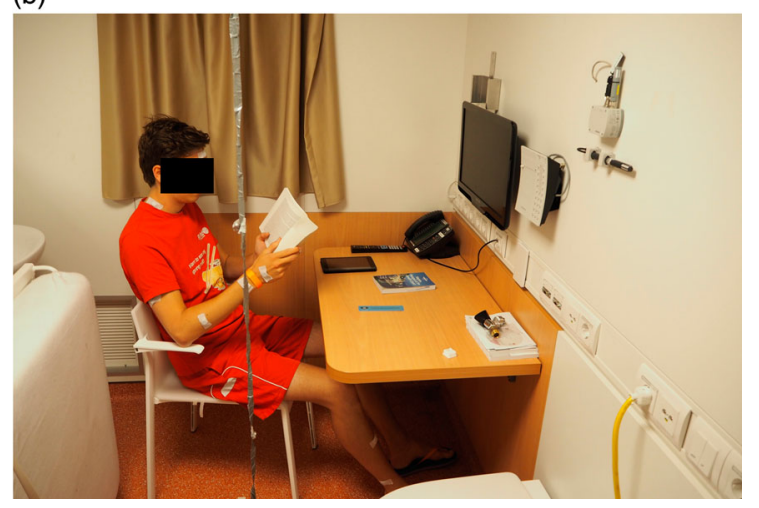

Figure 2. (a) Two representative climate chambers at the MRUM; and (b) a participant during SWITCH. During SWITCH, participants commuted between two climate chambers (a warm room at $37^{\circ} \mathrm{C}$ and a cold room at $17^{\circ} \mathrm{C}$ ). 
Upon arrival at the laboratory, the participants were asked to change into standardized clothing, consisting of underwear, T-shirt, shorts and slippers/socks. During the experiment, they sat on a chair. The total thermal resistance of the clothing ensemble plus the desk chair added to approximately 0.41 clo (McCullough, Jones, \& Tamura, 1989; McCullough, Olesen, \& Hong, 1994). Skin temperature was measured at 14 ISO-defined skin sites (ISO, 2004) to calculate mean skin temperature as well as proximal (body core) and distal (extremities) skin temperature. Skin temperatures were recorded at one-minute intervals throughout the whole protocol (iButton, Maxim Integrated Products, San Jose, California, USA). Air temperature and relative humidity were measured by means of wireless temperature/humidity sensors (Hygrochron iButton, DS1923, Maxim Integrated Products), according to EN-ISO 7726 (ISO, 2001). Moreover, participants were asked to rate their thermal environment using visual analogue scales (VAS). TS and TC votes were recorded every six minutes and an additional questionnaire was answered just before the initiation of a switch of rooms. TS was evaluated using the seven-point continuous ASHRAE TS scale ranging from -3 to 3 ( -3 cold, -2 cool, -1 slightly cool, 0 neutral, 1 slightly warm, 2 warm, 3 hot). TC was indicated on a continuous five-point VAS ranging from -2 very uncomfortable to 2 very comfortable (Figure 3).

\section{Warmth acclimation}

After the first SWITCH on day 1 of the study, the warmth acclimation period commenced (Figure 1(a)). Participants were exposed to $33.3 \pm 1.56^{\circ} \mathrm{C}$ ambient temperature with a relative humidity of $22.3 \% \pm 6.6 \%$ on seven consecutive days for six hours per day. During their stay, participants wore standardized clothing (underwear, T-shirts, shorts and beach slides (beach sandals), about 0.36 clo; McCullough et al., 1989) and they sat on an office chair (about 0.05 clo; McCullough et al., 1989). They were asked to perform regular office work (1.2 METs) and were allowed to leave the room for short toilet breaks. Participants were provided with food (sandwiches and crackers/cookies; three times in six hours) and water ad libitum.
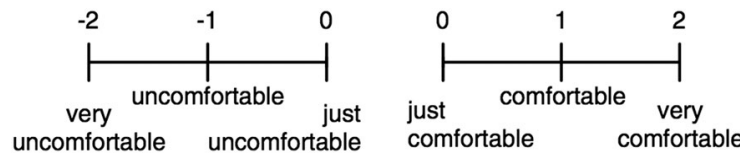

Figure 3. Thermal comfort scale ('how do you perceive your thermal environment?').

\section{Statistical analyses}

Data are presented as the mean $\pm \mathrm{SD}$ or as range between minimum and maximum. Matlab R2014a was used for data preparation and both Matlab R2014A and SPSS 22.0 for Mac (SPSS Inc.) were used for statistical data analyses. TRB was evaluated by (1) counting the total number of switches, (2) clocking the time participants remained in the warm and the cold room, and (3) by evaluating the course of their mean skin temperature, as the latter can represent an important predictor for TRB. Mean skin temperature as measured just before switching from the warm room to the cold room $\left(37 \rightarrow 17^{\circ} \mathrm{C}\right)$ indicated the upper critical behavioural threshold (UCBT), whereas mean skin temperature measured just before switching from the cold room to the warm room $\left(17 \rightarrow 37^{\circ} \mathrm{C}\right)$ marked the lower critical behavioural threshold (LCBT). Moreover, TS and TC votes upon the initiation of a switch were analysed. Paired $t$-tests were applied to test for statistical differences between pre- and post-acclimation measurements of skin temperature. Wilcoxon signedrank tests were used to test statistical differences between pre- and post-acclimation measurements of TRB, TS and TC. Statistical significance was assumed if $p \leq 0.05$. A trend was assumed when $0.05<p<0.10$.

\section{Results}

\section{Thermoregulatory behaviour: pre- and post- warmth acclimation}

Before acclimation, participants switched two to six times and spent a total amount of 17-77 $\mathrm{min}$ in the warm room and 12-74 min in the cold room (Table 2 and see Table S1 in the supplemental data online). After acclimation, participants switched zero to six times and the total amount of time spent in the warm room increased to $35-90 \mathrm{~min}$, whereas the time spent in the cold room decreased to 0-56 min (Table 2 and Table S1 in the supplemental data online). All individual movements between the warm and the cold rooms before and after warmth acclimation are represented in Figure 4, together with the matching mean skin temperatures and mean TS votes, as measured just before switching the conditions. Effects of season on the measured variables were ruled out by testing the effect of mean day outdoor temperature for each individual participant on TRB, TS, TC and mean skin temperatures.

\section{Mean skin temperature and thermoregulatory behaviour}

Before warmth acclimation, UCBTs ranged from 35.1 to $36.1^{\circ} \mathrm{C}$ and LCBTs from 30.0 to $32.9^{\circ} \mathrm{C}$. After 


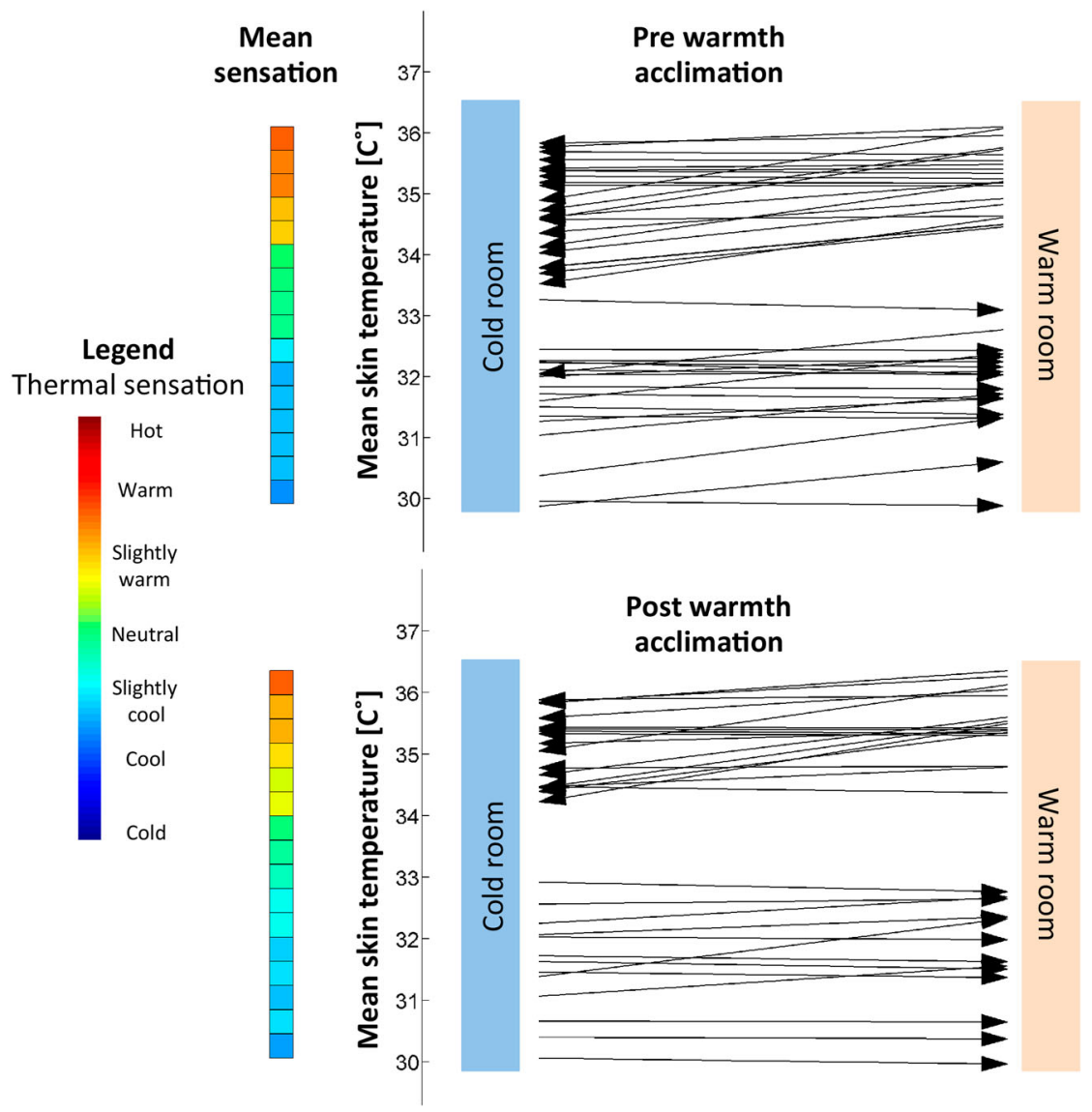

Figure 4. Individual switches pre- and post-warmth acclimation. Black arrows indicate all individual switches between the warm and the cold rooms after baseline, before (top) and after (bottom) warmth acclimation. The arrow origins and insertions indicate mean skin temperatures as measured upon leaving the original condition and arriving at the opposite condition. Mean sensation represents the mean of the sensation votes for the respective mean skin temperature just before switching. $N=12$.

acclimation, UCBTs ranged from 34.5 to $36.3^{\circ} \mathrm{C}$ and the LCBTs from 30.1 to $32.8^{\circ} \mathrm{C}$. As indicated in Table 2, the UCBT's significantly increased post-acclimation, but the LCBTs were not significantly different.

The range of mean skin temperatures between the two critical thresholds is described as a thermoregulatory

Table 2. Results of SWITCH pre- and post-warmth acclimation.

\begin{tabular}{lccc}
\hline & $\begin{array}{c}\text { Pre-warmth } \\
\text { acclimation }\end{array}$ & $\begin{array}{c}\text { Post-warmth } \\
\text { acclimation }\end{array}$ & $\begin{array}{c}\boldsymbol{p} \text { - } \\
\text { value }\end{array}$ \\
\hline Switches & $3.4 \pm 1.1$ & $2.5 \pm 1.5$ & 0.075 \\
$\begin{array}{l}\text { Stay in a warm room } \\
\text { (min) }\end{array}$ & $50.9 \pm 16.2$ & $56.9 \pm 14.7$ & 0.177 \\
Stay in a cold room (min) & $37.3 \pm 16.7$ & $31.9 \pm 14.4$ & 0.283 \\
UCBT $\left({ }^{\circ} \mathrm{C}\right)$ & $35.2 \pm 0.6$ & $35.5 \pm 0.5$ & $0.050^{*}$ \\
LCBT $\left({ }^{\circ} \mathrm{C}\right)$ & $31.6 \pm 0.9$ & $31.4 \pm 0.8$ & 0.585 \\
TBNZ & $3.6 \pm 0.7$ & $4.2 \pm 0.6$ & $0.027^{*}$ \\
\hline
\end{tabular}

Notes: $\mathrm{LCBT}=$ lower critical behavioural threshold, UCBT $=$ upper critical behavioural threshold, TBNZ = thermal behaviour-neutral zone, range of mean skin temperature within which no thermoregulatory behaviour occurred. Data are presented as the mean $\pm S D . N=12$. ${ }^{*} P \leq 0.05$. behaviour neutral zone (TBNZ), thus the range of mean skin temperature within which no switch occurred. The smallest observed range of TBNZ before acclimation was $32.3-35.3^{\circ} \mathrm{C}$ (range $=3.08^{\circ} \mathrm{C}$ ) and $30.46-33.63^{\circ} \mathrm{C}$ (range $=3.34^{\circ} \mathrm{C}$ ) after warmth acclimation. The largest observed range of TBNZ before acclimation was $29.97-35.14^{\circ} \mathrm{C}$ ( range $=5.17^{\circ} \mathrm{C}$ ) and $30.38-34.87^{\circ} \mathrm{C}$ mean skin temperature (range $=5.09^{\circ}$ C) after warmth acclimation. As indicated in Table 2, the TBNZ widened significantly post-warmth acclimation and increased from averagely $31.5 \pm 0.9-35.2 \pm$ $0.6^{\circ} \mathrm{C}$ pre-warmth acclimation to $31.4 \pm 0.8-35.5 \pm 0.5^{\circ}$ $\mathrm{C}$ post-warmth acclimation. All individual TBNZ ranges are presented in Figure 5. For participant 5, no TBNZ could be calculated as the participant did not switch post-acclimation but remained in the warm room throughout the entire SWITCH period $(90 \mathrm{~min}$ after baseline). For participant 9, no LCBT could be indicated since they only switched once from the warm to the cold room and then remained in the cold condition until the end of SWITCH. 


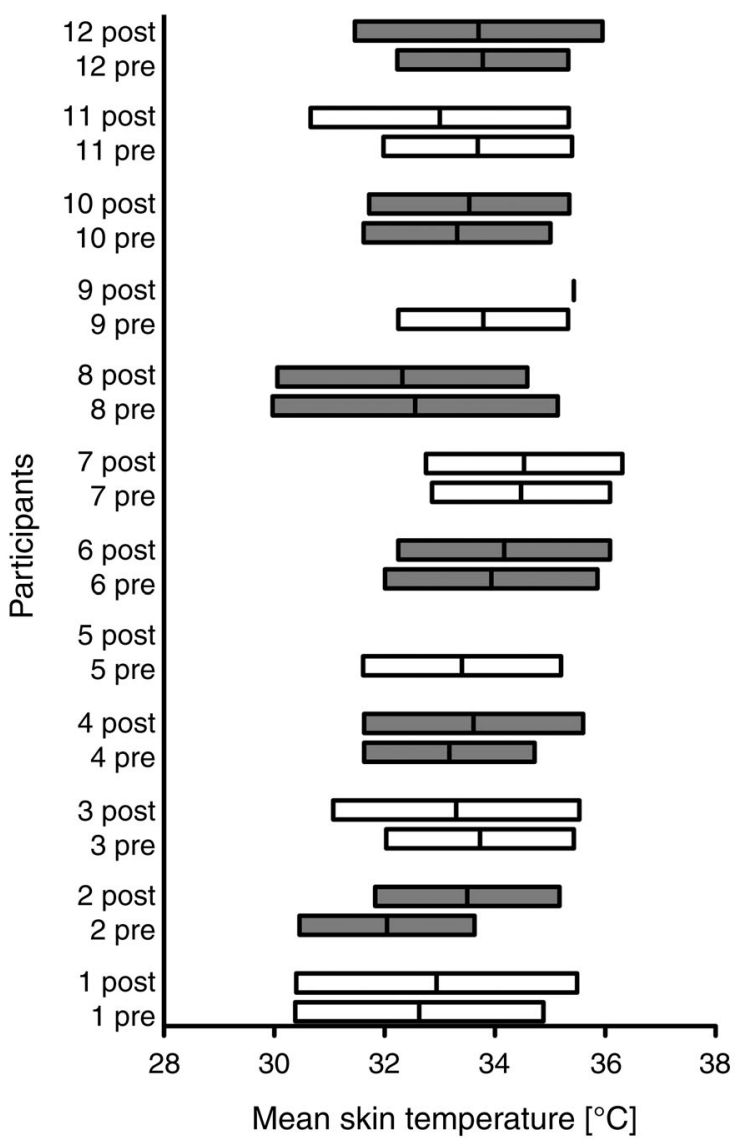

Figure 5. Individual thermoregulatory behaviour neutral zones (TBNZs) of all participants pre- and post-warmth acclimation. Alternating shading is applied to illustrate the pairs of TBNZ belonging to one participant.

\section{Thermal perception during SWITCH}

The perception of the thermal environment at the UCBT and LCBT was represented by the TS and TC votes submitted by participants just before switching rooms. The

Table 3. Thermal sensation and thermal comfort at the lower and upper critical behavioural temperatures during SWITCH pre- and post-warmth acclimation.

\begin{tabular}{lrcr}
\hline & Mean \pm SD & Minimum & Maximum \\
\hline Sensation & & & \\
LCBT pre & $-1.3 \pm 1.3$ & -2.9 & 2.3 \\
UCBT pre & $1.4 \pm 0.9$ & -0.5 & 2.4 \\
LCBT post & $-1.3 \pm 0.5$ & -2.1 & -0.4 \\
UCBT post & $1.5 \pm 0.5$ & 0.9 & 2.4 \\
& & & \\
Comfort & & & \\
LCBT pre & $0.1 \pm 0.8$ & -1.1 & 2.0 \\
UCBT pre & $-0.1 \pm 0.3$ & -0.6 & 0.3 \\
LCBT post & $0.3 \pm 0.7$ & -0.5 & 2.0 \\
UCBT post & $0.0 \pm 0.3$ & -0.5 & 0.6
\end{tabular}

Note: LCBT = lower critical behavioural threshold, UCBT = upper critical behavioural threshold. No significant difference was detected between LCBT's and UCBT's pre- and post-warmth acclimation. $N=12$. minimum, maximum and range of votes at the LCBT and UCBT (within the TBNZ) before and after warmth acclimation are presented in Table 3. TS and TC votes within the TBNZ are presented in Figure S1 in the supplemental data online. TS and TC at UCBT and LCBT were not significantly influenced by warmth acclimation.

\section{Discussion and conclusions}

The present evaluated the effect of passive warmth acclimation on TRB, skin temperature, TS and thermal perception. In accordance with our hypothesis, we showed that only seven days of passive warmth acclimation significantly influenced mean skin temperature and TRB. Post-acclimation, participants switched at significantly higher mean skin temperatures (higher UCBT), thereby broadening the range of mean skin temperatures at which no TRB occurred (TBNZ). Moreover, the total amount of switches tended to decreased post-acclimation $(p=0.075)$. TS and TC, however, did not significantly change after warmth acclimation.

It has previously been suggested that core and skin temperature are the driving forces for TRB (Cabanac et al., 1971; Chatonnet et al., 1966). More recently, Schlader et al. (2013) and Schlader, Prange, Mickleborough, and Stager (2009) emphasized the importance of skin temperature in mediating behavioural thermoregulation, especially in mild thermal environments. Core temperature has been found to play a less important role, which might be due to the nature of the concept itself: the goal of both physiological and behavioural thermoregulation is to buffer (substantial) changes in core temperature and to ensure thermal balance (IUPS Thermal Commission, 2003; Schlader, Stannard, \& Mundel, 2010). We therefore decided to focus on skin temperature as a determining factor for TRB.

Generally, knowledge on the driving forces of behavioural thermoregulation in humans is very limited, which is surprising, considering the important role that TRB plays in human thermoregulation. After all, thermal physiology (e.g. vasomotion, sweating and cold-induced thermogenesis) has relatively limited capacity, whereas the capability of TRB is virtually unlimited (Benzinger, 1969; Schlader et al., 2010). From the present authors' thermophysiological studies, it is known that the individual variation in thermal responses is great: sex, age, body composition and metabolism influence the range of preferred temperatures and thereby codetermine TRB (Jacquot et al., 2014; Schellen, Loomans, de Wit, Olesen, \& van Marken Lichtenbelt, 2012; Schellen, van Marken Lichtenbelt, Loomans, Toftum, \& de Wit, 2010). Besides that, the state of acclimatization is of significant importance. Our results indeed show considerable individual variation 
of TRB. For example, the amount of total switches between warm and cold ranged from zero to six. Moreover, time spent in one of the respective conditions greatly varied between participants and, as depicted in Figure 4, the width and range of TBNZs notably differed.

Above that, sensation and comfort votes provided at the initiation of a switch were remarkably varied between participants. As indicated in Table 3, switching occurred at TS votes ranging between cold and warm for the LCBT and slightly between cold and hot for the UCBT. As for TC, votes varied between uncomfortable and very comfortable for the LCBT and between uncomfortable and just uncomfortable and between just comfortable and comfortable for the UCBT (Table 3). The range of TS and TC votes within the TBNZ tended to decrease after warmth acclimation. The latter indicates that the thermal environment was perceived as less extreme and less uncomfortable, considering the tendency for fewer switches post-acclimation. On average, switching to the warm room occurred when participants were feeling cool but just comfortable, whereas the switch to the cold room was initiated when the thermal environment was perceived between warm and hot and just uncomfortable to just comfortable, respectively. Participants thus tended to preserve their state of comfort and switched to the respective opposite condition, already before a distinct state of discomfort was established. The latter was even more pronounced after warmth acclimation, but the trend was not significant.

To the best of our knowledge, the present study is the first to investigate the effect of passive mild warmth acclimation on TRB. The findings indicate that prolonged passive exposure to warmth extends the behavioural threshold for warm conditions. Participants seem to tolerate higher mean skin temperatures before they feel the need to regulate their body temperature. Moreover, great individual variation for all the measured parameters was evident. Although the effects of warmth acclimation on UCBT and TBNZ were moderate on a group level, the results are of statistical and physiological significance. This information could be of importance for the design and management of future indoor thermal environments. Building energy expenditure could easily be lowered by using a less strict air-conditioning setpoint without affecting occupant satisfaction.

With respect to practical implications, the findings suggest that acclimatized occupants of an overheated building might tolerate higher skin temperatures without feeling the need to change their thermal environment. Participants tolerated approximately $0.3^{\circ} \mathrm{C}$ higher mean skin temperatures after only seven days of warmth acclimation. Although the effect on mean skin temperature was relatively small, a toleration of $0.3^{\circ} \mathrm{C}$ higher mean skin temperatures implies a reduced cooling demand for HVAC systems (equal to $0.3^{\circ} \mathrm{C}$, assuming a constant temperature gradient between skin and air temperature to maintain heat balance, and neglecting effects on evaporation either due to humidity (physical) or perspiration (physiological). Reducing the cooling need by increasing the air-conditioning set-point by only $0.4^{\circ} \mathrm{C}$ may already lead to yearly savings of approximately 5\% (Hoyt, Arens, \& Zhang, 2015). Furthermore, prolongation of the acclimation period might lead to the tolerance of even higher mean skin temperatures, which might subsequently lead to even greater savings.

The present study provides an important first step towards the better understanding of physiological, subjective and behavioural changes post-warmth acclimation. It was designed to develop fundamental knowledge on the interaction physiology, subjective and behavioural factors. However, with respect to the general interpretation of the study results, a few limitations need to be taken into consideration. Firstly, only healthy young men were studied, limiting the transferability of the results to the general population. Secondly, the experiments were performed in a very controlled laboratory environment and, therefore, the results might not be directly transferrable to practical settings in the built environment. Temperatures applied in the SWITCH protocol, dependent on the climate zone in question, were likely to be more extreme than those usually encountered in buildings. Finally, the experiment's long duration (nine months in total), which was needed to carry out all measurements, should be taken into consideration. Since the study was carried out over three different seasons (winter, spring and summer), it was possible to test the effect of season (mean day outdoor temperature two weeks before commencing the measurement for each individual) on the measured parameters TS, TC and mean skin temperature. None of the parameters was significantly affected, minimizing bias by seasonal temperature differences. Although it has been tested and concluded that season did not influence the results, the long study period might have alleviated the effects.

Future research should focus on the evaluation of TRB and prolonged warmth exposure in a larger, more diverse population of both men and women. Moreover, field studies are needed to establish and verify the results under realistic, less controlled indoor conditions.

\section{Acknowledgements}

The authors express their gratitude to Paul Schoffelen, Loek Wouters and Marc Souren, Metabolic Research Unit Maastricht (MRUM), for their assistance and technical support. Moreover, they express their appreciation to all volunteers for their participation. 


\section{Disclosure statement}

No potential conflict of interest was reported by the authors.

\section{Funding}

The study was supported by Agentschap NL [grant number EOS-LT 10033 INTEWON] and TKI Energo/TKI Solar Energy [grant number TEGB 113023].

\section{ORCID}

Hannah Pallubinsky (D) http://orcid.org/0000-0002-1181-1277

\section{References}

AECOM. (2012). Investigation into overheating of homes: Literature review. London: Department for Communities and Local Government.

American Society of Heating, Refridgerating and Air Conditioning Engineers (ASHRAE). (2010). The environmental conditions for human occupancy standard 55-2010. Atlanta, GA: ASHRAE.

Benzinger, T. H. (1969). Heat regulation: Homeostasis of central temperature in man. Physiological Review, 49(4), 671-759.

Cabanac, M., Cunningham, D. J., \& Stolwijk, J. A. (1971). Thermoregulatory set point during exercise: A behavioral approach. Journal of Comparative and Physiological Psychology, 76(1), 94-102. doi:10.1037/h0031050

Chatonnet, J., Thiers, H., Cabanac, M., \& Pasquier, J. (1966). [On the origin of conscious impression of thermal comfort]. Lyon Medicial, 216(50), 1387-1392.

de Dear, R. J., Akimoto, T., Arens, E. A., Brager, G., Candido, C., Cheong, K. W., ... Zhu, Y. (2013). Progress in thermal comfort research over the last twenty years. Indoor Air, 23 (6), 442-461. doi:10.1111/ina.12046

Edholm, O. G., \& Weiner, J. A. (1981). The principles and practice of human physiology. London: Academic Press Inc.

Fox, R. H., Goldsmith, R., Kidd, D. J., \& Lewis, H. E. (1963). Blood flow and other thermoregulatory changes with acclimatization to heat. The Journal of Physiology, 166, 548-562. doi:10.1113/jphysiol.1963.sp007122

Gagge, A. P., Stolwijk, J. A. J., \& Hardy, J. D. (1967). Comfort and thermal sensations and associated physiological responses at various ambient temperatures. Environmental Research, 1(1), 1-20. doi:10.1016/0013-9351(67)90002-3

Hoyt, T., Arens, E., \& Zhang, H. (2015). Extending air temperature setpoints: Simulated energy savings and design considerations for new and retrofit buildings. Building and Environment, 88, 89-96. doi:10.1016/j.buildenv.2014.09.010

IEA. (2011). ECBCS annual report 2011, energy conservation in buildings \& community systems programme. Hertfordshire. Retrieved from http://www.ecbs.org

International Standards Organization (ISO). (2001). Ergonomics of the thermal environment - Instruments for measuring physical quantities ISO 7726:2001. Geneva: ISO.

International Standards Organization (ISO). (2004). Ergonomics - Evaluation of thermal strain by physiological measurements ISO 9886:2004. Geneva: ISO.
IPCC. (2013). Climate change 2013 - The Physical Science Basis. Switzerland. Retrieved from http://www.climatechange2013. org/images/report/WG1AR5_ALL_FINAL.pdf

IUPS Thermal Commission. (2003). Glossary of terms for thermal physiology. Journal of Thermal Biology, 28, 75106. doi:10.1016/S0306-4565(02)00055-4

Jacquot, C. M., Schellen, L., Kingma, B. R., van Baak, M. A., \& van Marken Lichtenbelt, W. D. (2014). Influence of thermophysiology on thermal behavior: The essentials of categorization. Physiology \& Behavior, 128, 180-187. doi:10.1016/j. physbeh.2014.01.025

Klepeis, N. E., Nelson, W. C., Ott, W. R., Robinson, J. P., Tsang, A. M., Switzer, P., ... Engelmann, W. H. (2001). The National Human Activity Pattern Survey (NHAPS): A resource for assessing exposure to environmental pollutants. Journal of Exposure Analysis and Environmental Epidemiology, 11(3), 231-252. doi:10.1038/sj.jea.7500165

Lomas, K. J., \& Porritt, S. M. (2017). Overheating in buildings: Lessons from research. Building Research \& Information, 45 (1-2), 1-18. doi:10.1080/09613218.2017.1256136

McCullough, E. A., Jones, B. W., \& Tamura, T. A. (1989). A database for determining the evaporative resistance of clothing. ASHRAE Transactions, 95(13), 316-328.

McCullough, E. A., Olesen, B. W., \& Hong, S. (1994). Thermal insulation provided by chairs. ASHRAE Transactions, 100(8), 795-802.

Schellen, L., Loomans, M. G., de Wit, M. H., Olesen, B. W., \& van Marken Lichtenbelt, W. D. (2012). The influence of local effects on thermal sensation under non-uniform environmental conditions-Gender differences in thermophysiology, thermal comfort and productivity during convective and radiant cooling. Physiology \& Behavior, 107 (2), 252-261. doi:10.1016/j.physbeh.2012.07.008

Schellen, L., van Marken Lichtenbelt, W. D., Loomans, M. G., Toftum, J., \& de Wit, M. H. (2010). Differences between young adults and elderly in thermal comfort, productivity, and thermal physiology in response to a moderate temperature drift and a steady-state condition. Indoor Air, 20(4), 273-283. doi:10.1111/j.1600-0668.2010.00657.x

Schlader, Z. J., Perry, B. G., Jusoh, M. R., Hodges, L. D., Stannard, S. R., \& Mundel, T. (2013). Human temperature regulation when given the opportunity to behave. European Journal of Applied Physiology, 113(5), 12911301. doi:10.1007/s00421-012-2544-0

Schlader, Z. J., Prange, H. D., Mickleborough, T. D., \& Stager, J. M. (2009). Characteristics of the control of human thermoregulatory behavior. Physiology \& Behavior, 98(5), 557-562. doi:10.1016/j.physbeh.2009.09.002

Schlader, Z. J., Simmons, S. E., Stannard, S. R., \& Mundel, T. (2011). The independent roles of temperature and thermal perception in the control of human thermoregulatory behavior. Physiology \& Behavior, 103(2), 217-224. doi:10. 1016/j.physbeh.2011.02.002

Schlader, Z. J., Stannard, S. R., \& Mundel, T. (2010). Human thermoregulatory behavior during rest and exercise-A prospective review. Physiology \& Behavior, 99(3), 269-275. doi:10.1016/j.physbeh.2009.12.003

Taylor, N. A. (2014). Human heat adaptation. Comprehensive Physiology, 4(1), 325-365. doi:10.1002/cphy.c130022

Turk, A. J., \& Thomas, I. R. (1975). Artificial acclimatization to heat. Annals of Occupational Hygiene, 17, 271-278. doi:10. 1093/annhyg/17.3-4.271 